\title{
A case of recto-vaginal obstetrical fistula treated by the Martius lamp, seen at Befelatanana Madagascar
}

\author{
Rainibarijaona Lanto ${ }^{1}$, Rakotonirina Martial ${ }^{1 *}$, Rakotozanany Besaina ${ }^{1}$, Ratsiatosika \\ Tanjona $^{1}$, Randriamahavonjy Romuald ${ }^{2}$, Andrianampanalinarivo Rakotovao Hery ${ }^{1}$
}

\author{
${ }^{1}$ Department of Gynecology Obstetrics, Befelatanana University Hospital Centre of Obstetric Gynecology in \\ Antananarivo, Madagascar \\ ${ }^{2}$ Department of Gynecology Obstetrics, Soavinandriana Hospital Center, Antananarivo, Madagascar
}

Received: 30 September 2019

Revised: 21 May 2020

Accepted: 28 May 2020

*Correspondence:

Dr. Rakotonirina Martial,

E-mail: andriamarorakotonirina@gmail.com

Copyright: (c) the author(s), publisher and licensee Medip Academy. This is an open-access article distributed under the terms of the Creative Commons Attribution Non-Commercial License, which permits unrestricted non-commercial use, distribution, and reproduction in any medium, provided the original work is properly cited.

\begin{abstract}
The rectovaginal fistulas are a pathological epithelialized communication between the vagina and the rectum, its frequency is 10 to $30 \%$, and it is a disabling pathology because of the social repercussion. Many flap techniques have been described but the aim is to present a simple procedure according to a particular technique called Martius. This is a case of woman presenting a low rectovaginal fistula on obstetrical trauma. The surgical technique consists of a repair according to the technique of Martius. The operative follow-up was simple and the patient was able to resume sexual activity and normal anal sphincter function. It is a simple technique, easy to achieve for the technical platform in Madagascar whose evaluation of the results for a larger population should be considered. This technique therefore deserves to be known and widely used.
\end{abstract}

Keywords: Martius flap, Obstetrical trauma, Perineal repair, Rectovaginal fistulas, Surgery

\section{INTRODUCTION}

The rectovaginal fistulas are a pathological epithelialized communication between the vagina and the rectum through the rectovaginal septum. Of more frequent etiology, most often of obstetric origin. Rectovaginal fistula accounts for approximately 10 to $30 \%$ obstetric fistulas. ${ }^{1}$

It is a common and disabling pathology. Every year around the world, 50000 to 100000 women have obstetric fistula. Across the world, but especially in subSaharan Africa and Asia, it is generally estimated that more than 2 million young women live with untreated obstetric fistula. $^{2}$ Millions of girls and women in resource-poor countries live in shame and isolation, often abandoned by their husbands and excluded by their families and communities. ${ }^{3}$ The most common surgical repairs the flap technique. ${ }^{4}$ The Martius flap technique is a technique that is rarely used in the treatment of complex rectovaginal fistulas and the most common indications for the Martius flap are iatrogenic fistulas, radiation fistulas and the failures of all other techniques. ${ }^{5}$

The objective of this study is to report the therapeutic aspect of a case of obstetric recto-vaginal complication fistula according to a technique of Martius.

\section{CASE REPORT}

It was a young patient aged 32 paucipara, no significant pathological history that was admitted to the Befelatanana Maternity Service on April 6, 2011 for an involuntary loss of stool. 
In her delivery history in 2010, which was a dystocic labor, the presentation was cephalic with an isolated fetal head. The extraction of a stillborn, had been done by intractable third-degree perineal tear unrepaired, without notion of instrumental extraction. The evolution was marked by the appearance 5 days after delivery, stool leakage through the vaginal cavity, without urinary leakage with retention of urination.

The urogenital examination revealed a complete posterior perineal tear at the inspection.

Valve examination showed direct communication between the rectum and the vagina on the lower third of about $4 \mathrm{~cm}$, rectal and vaginal bruise and fibrosis, the presence of feces in the vagina, there was no vesicovaginal fistula. At the end of the interrogation and clinical examination, the diagnosis of a complex obstetric rectovaginal fistula was discussed.

It was impossible to perform an immediate surgical repair.

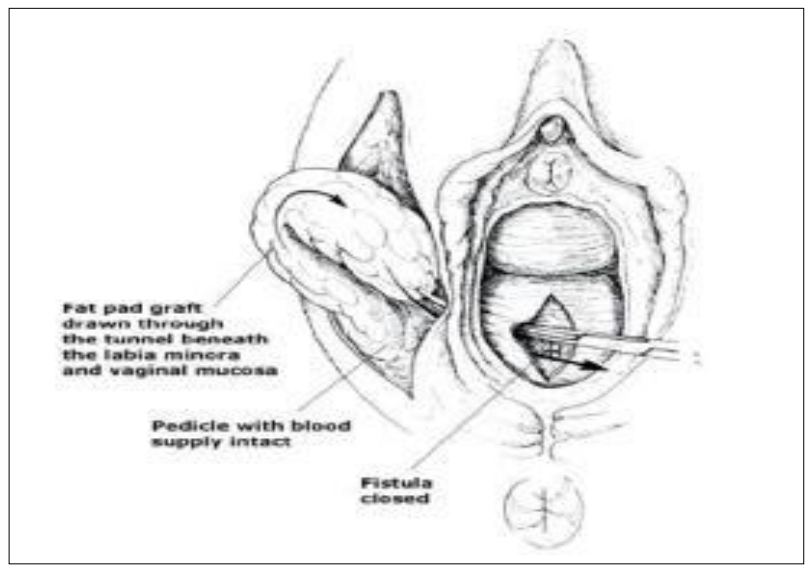

Figure 1: Flap interposition in the rectovaginal roofing.

\section{1st stage: separation of the vaginal and rectal mucosa}

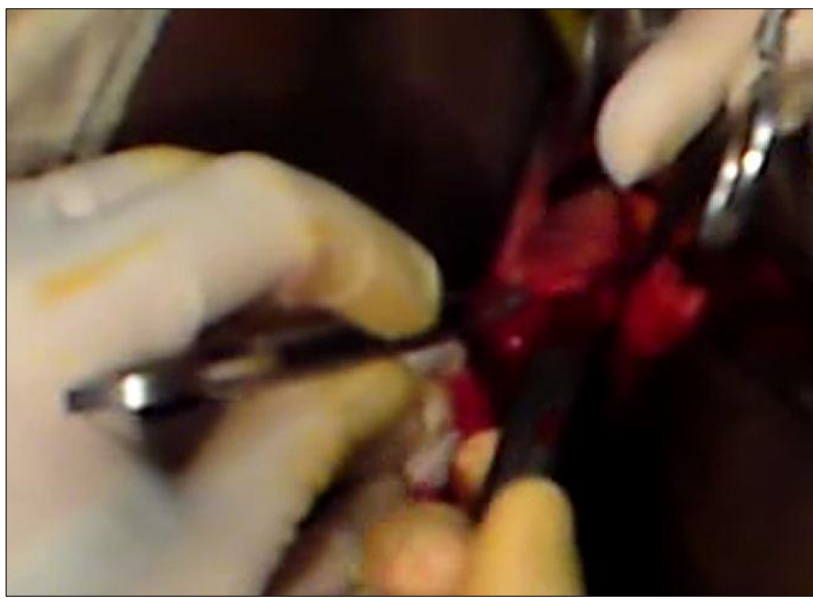

Figure 2: Separation of the vaginal and rectal mucosa.
The patient had undergone surgical treatment of rectovaginal fistula using the Martius procedure with interposition between the vaginal and rectal cavernous bulbo muscle (Figure 1). The vascular pedicle was preserved without a bypass stoma.

It seems that a simple enema evacuator the day before the intervention is sufficient to prepare the tissues. No digestive preparation. No diet without residues postoperatively.

She is installed in a gynecological position. Once the painting is done, a foley-type catheter is introduced into the bladder and is kept for a few days because of the risk of early acute retention.

\section{$2^{\text {nd }}$ step: closure rectal mucosa}

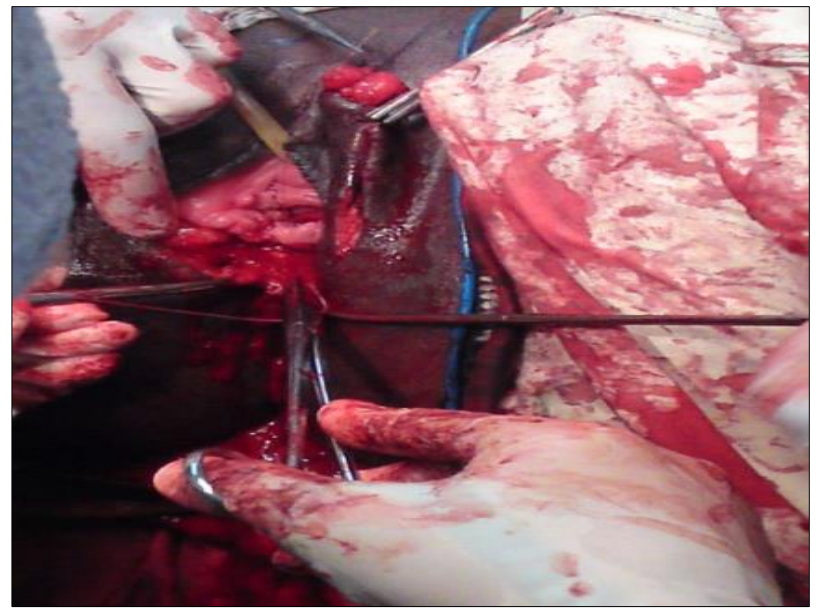

Figure 3: Closure rectal mucosa.

\section{$3^{\text {rd }}$ time: left vulvar approach.}

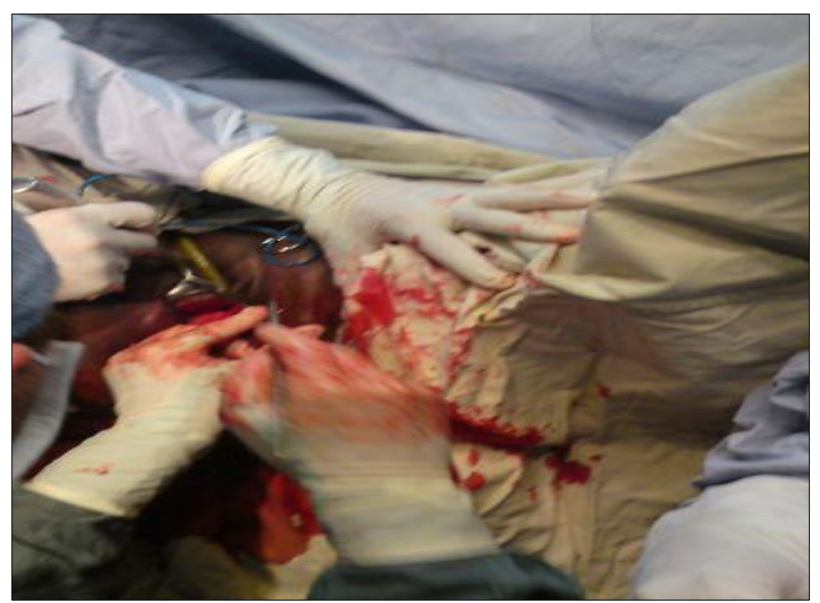

Figure 4: Left vulvar approach.

The flattening is performed by direct section with the cold knife. This resection is facilitated by the median perineotomy, it consists of an anal and vaginal bank and 
the resection of inflammatory tissues bordering the fistula (Figure 2).

The Allis forceps come to seize the banks of the vaginal incision and are raised to prepare the rectovaginal dissection plan. The torn anal sphincter is sutured (Figure $3)$.

The skin of the large lip is detached laterally towards the vaginal cavity and the groin inguinocrural to perfectly expose in its width the bulbocavernosus muscle (Figure 4). This muscle is cautiously dissected from the deep plane (femoral aponeurosis) and a lake is crossed transversely under its fleshy body, facing the middle part of the large lip. Light traction towards the rear, and the forward spacing using a Farabeuf retractor allows to release a length of muscle of about $8 \mathrm{~cm}$.

\section{$4^{\text {th }}$ time: sampling bulbo-spongy muscle}

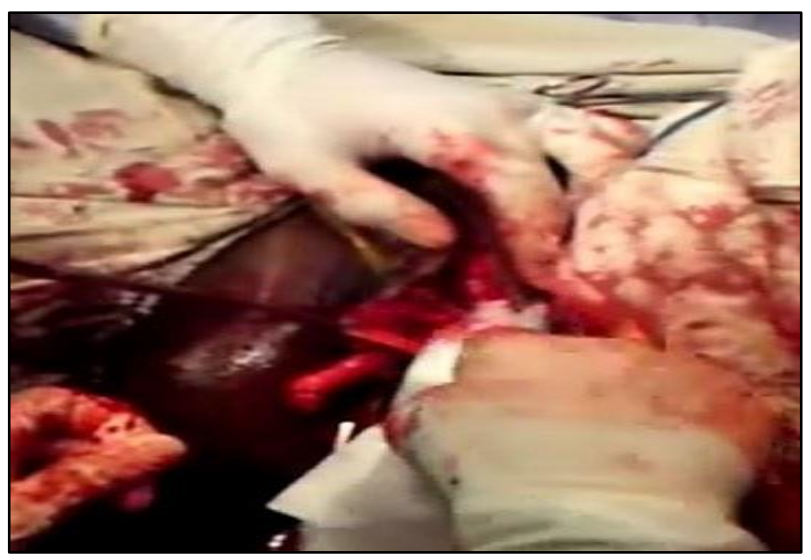

Figure 5: Sampling bulbo-spongy muscle.

\section{$5^{\text {th }}$ time: Bulbo-spongy muscle interposition}

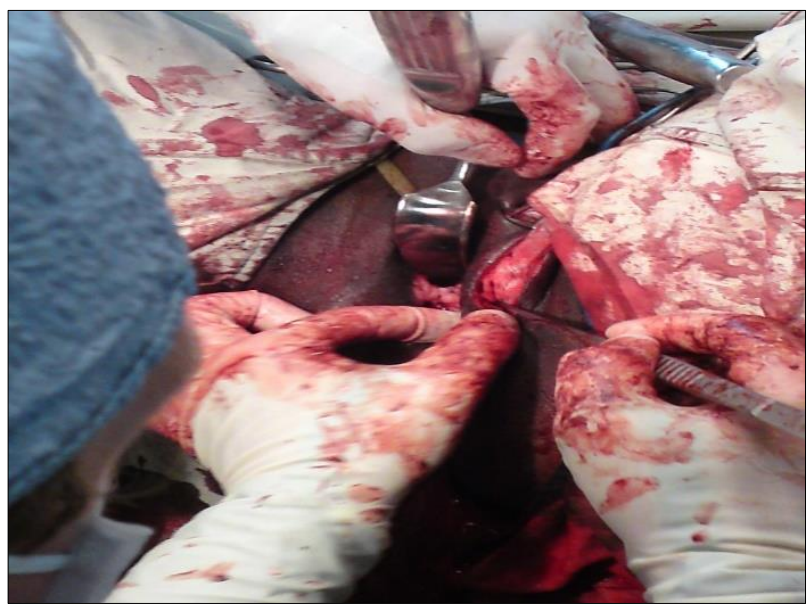

Figure 6: Bulbo-spongy muscle interposition.

The hinge is posterior imperatively, because it is by this pole that the nourishing vessels from the pudendal artery and vein approach the muscle. The muscle is then sectioned at its anterior part and placed temporarily under a compress soaked with warm serum (Figure 5).

An interposition of the spongy bulbo muscle between the rectum and the vagina was performed (Figure 6).

Low levator myorrhaphy or external sphincteroplasty can be performed (Figure 7)

\section{$6^{\text {th }}$ time: external sphincteroplasty}

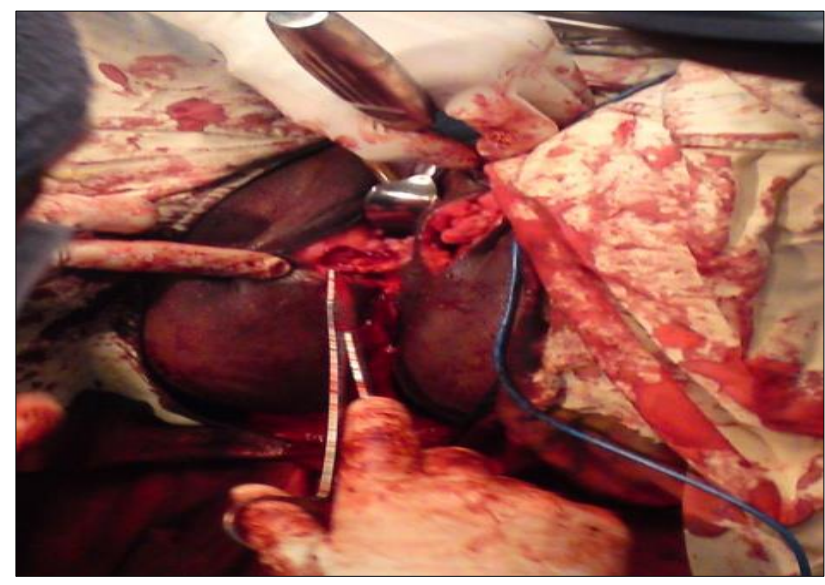

Figure 7: External sphincteroplasty.

\section{7th time: vulvar closure}

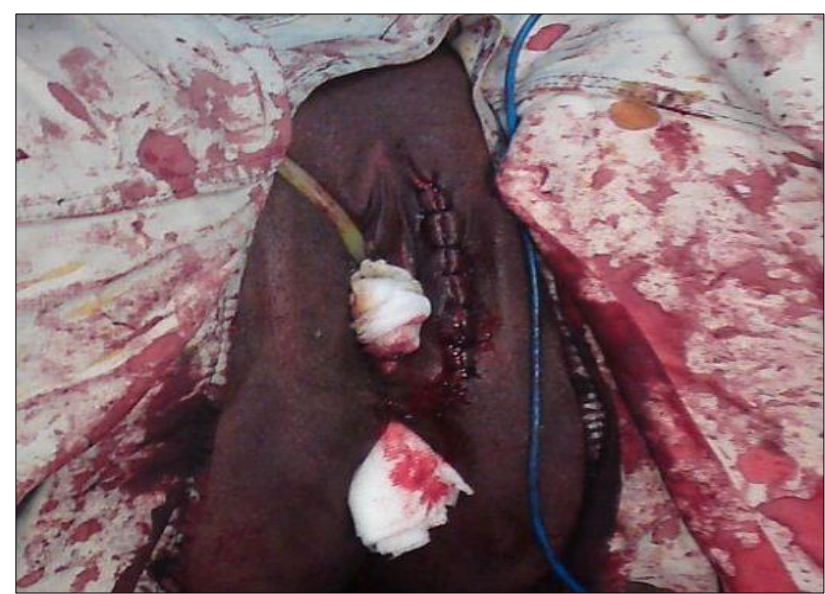

Figure 8: Vulvar closure.

The vaginal mucosa is closed on the flap by several separate points of slowly absorbable 3/0 wire without drainage.

The skin of the large lip is closed with separate points of $3 / 0$ no absorbable thread (Figure 8).

The evolution was marked by simple immediate operative follow-up, a resumption of sexual activity at 6 months postoperatively and no complication was observed postoperatively. To this day, there will be no 
recurrence of fistula with good continence; he had a successful intervention.

\section{DISCUSSION}

Despite the progress of public health in our country (UNFPA), obstetric fistula remains one of the major gynecological problems. Obstetric trauma remains the leading cause of obstetric fistula in developing countries. Indeed, prolonged work on a dystocic situation results in ischemic compression of the bladder in front and back of the rectum, against the bony structures of the pelvis, by the fetal head enclaved, this phenomenon leads to tissue necrosis with appearance of vesicovaginal fistulae and rectovaginal. $^{6}$ In this context, despite great efforts to improve the quality of obstetric care for pregnant women, there are still cases of obstetric rectovaginal fistula.

Rectovaginal fistula is a difficult clinical condition to treat. There are no national or international treatment recommendations. The data available in the literature are vague and do not allow to define an optimal treatment. There is little literature on the use of the Martius flap to treat a rectovaginal fistula.

In this context, despite great efforts to improve the quality of obstetric care for pregnant women, there are still cases of obstetric rectovaginal fistula.

Rectovaginal fistula is a difficult clinical condition to treat. There are no national or international treatment recommendations. The data available in the literature are vague and do not allow to define an optimal treatment. There is little literature on the use of the Martius flap to treat a rectovaginal fistula.

In this case, it was a rectovaginal fistula with an external sphincter lesion of the anus that was treated with Martius flap associated with a successful sphincteroplasty like that found by Aartsen in 1998 in his case. ${ }^{7}$

In the literature, the treatment of obstetric fistulas by the flap was common practice with satisfactory results and especially used in the treatment of vesico-vaginal fistula. ${ }^{8}$

The flap of Martius is one of the last techniques and is mainly aimed at rectovaginal fistula with the following characteristics: a rectal primary orifice above the dentate line (otherwise, fistulotomy should be preferred); a high vaginal secondary orifice located (otherwise, it would be necessary to start with gluing or direct suturing); a deep fistulous tract, involving more than one-third of the sphincter height as in the higher trans-sphincteric fistulas and supra-sphincteric fistulas (low trans-sphincteric fistulas and subcutaneous fistulas would be treated by simple fistulotomy); a pathological rectum (if it is healthy, the technique of choice is the flap of rectal lowering); the absence of active suppuration (otherwise, it is necessary to go through a phase of drainage in concrete); normal continence (otherwise the treatment could be a fistulotomy or a stoma). The most common indications for the flap of Martius are thus fistulas iatrogenic, radiation fistulas and failures of all other techniques (thus mimicking an iatrogenic fistula). ${ }^{5}$

A stoma of derivation is often performed at first, to allow healing of flap, outside an atmosphere that may be contaminated by the presence of stool which was not in this case. ${ }^{6}$

The advantages of the Martius technique are multiple: vascular reliability, a simple technique, easy to perform, an intervention in one time, a direct closure of the donor site and an aesthetic prejudice. ${ }^{9}$

\section{CONCLUSION}

Obstetric trauma remains the leading cause of rectovaginal fistula but is less common than vesicovaginal fistula. The Martius flap is a simple technique, effective in the treatment of complex rectovaginal fistula. This is an easy technique to achieve for the technical plateau in Madagascar in evaluating the results for a larger population should be considered. This technique therefore deserves to be known and widely used.

\section{Funding: No funding sources \\ Conflict of interest: None declared \\ Ethical approval: Not required}

\section{REFERENCES}

1. Manaouil D, Dumont F, Regimbeau JM, Duval H, Brazier F, Dupas JL, et al. Acquired rectovaginal fistulas of the adult. Gastroenterol Clin Biol. 2004;28:1267-79.

2. WHO. 10 facts on obstetric fistula. Geneva: World Health Organization; 2014. Available at: http://www.who.int/features/factfiles/obstetric_fistul a/en/. Accessed on 10 ${ }^{\text {th }}$ August 2019.

3. De Bernis L. Obstetric fistula: guiding principles for clinical management and programme development. World Health Organization; 2006.

4. Sonoda T, Hull T, Piedmont MR, Fazio VW. Outcomes of primary repair of anorectal and rectovaginal fistulas using the endorectal advancement flap. Say Colon Rectum. 2002;45:1622-8.

5. Faucheron JL, Brugere Ch, Lisik F. The flap of Martius: surgical technique. J Chir. 2006;143:5.

6. Tebeu PM, Fomulu JN, Khaddaj S, Bernis L, Delvaux $\mathrm{T}$, Rochat $\mathrm{CH}$. Risk factors for obstetric fistula: a clinical review. Int Urogynecol J. 2012;23(4):387-94.

7. Claude D, Ludovic F. Surgical management of obstetric fistulae Bull. Acad Natle Med. 2012;196(8):1535-56.

8. Aartsen EJ, Sindram IS. Repair of the radiationinduced rectovaginal fistulas with interposition of the 
bulbocavernosus muscle (Martius procedure). Eur J Surg Oncol. 1988;14(2):171-7.

9. Falandry L, Lahaye F, Marara C. The cutaneous pedicled flap fat of the large lip in the treatment of complex vesico-vaginal fistulas. About 11 cases. J Urol (Paris); 1990:96(2):97-102.
Cite this article as: Lanto R, Martial R, Besaina R, Tanjona R, Romuald R, Hery AR. A case of rectovaginal obstetrical fistula treated by the Martius lamp, seen at Befelatanana Madagascar. Int J Reprod Contracept Obstet Gynecol 2020;9:3058-62. 